\title{
Pulmonary eosinophilia*
}

\author{
Eosinofilia pulmonar \\ Luiz Eduardo Mendes Campos, Luiz Fernando Ferreira Pereira
}

\begin{abstract}
Pulmonary eosinophilia comprises a heterogeneous group of diseases defined by eosinophilia in pulmonary infiltrates (bronchoalveolar lavage fluid) or in tissue (lung biopsy specimens). Although the inflammatory infiltrate is composed of macrophages, lymphocytes, neutrophils and eosinophils, eosinophilia is an important marker for the diagnosis and treatment. Clinical and radiological presentations can include simple pulmonary eosinophilia, chronic eosinophilic pneumonia, acute eosinophilic pneumonia, allergic bronchopulmonary aspergillosis and pulmonary eosinophilia associated with a systemic disease, such as in Churg-Strauss syndrome and hypereosinophilic syndrome. Asthma is frequently concomitant and can be a prerequisite, as in allergic bronchopulmonary aspergillosis and Churg-Strauss syndrome. In diseases with systemic involvement, the skin, the heart and the nervous system are the most affected organs. The radiological presentation can be typical, or at least suggestive, of one of three types of pulmonary eosinophilia: chronic eosinophilic pneumonia, acute eosinophilic pneumonia and allergic bronchopulmonary aspergillosis. The etiology of pulmonary eosinophilia can be either primary (idiopathic) or secondary, due to known causes, such as drugs, parasites, fungal infection, mycobacterial infection, irradiation and toxins. Pulmonary eosinophilia can be also associated with diffuse lung diseases, connective tissue diseases and neoplasia.
\end{abstract}

Keywords: Pulmonary eosinophilia; Hypereosinophilic syndrome; Aspergillosis, allergic bronchopulmonary; Churg-Strauss syndrome.

\section{Resumo}

As formas de eosinofilia pulmonar constituem um grupo heterogêneo definido pela presença de um ou dois critérios: infiltrado pulmonar com eosinofilia sanguínea e/ou eosinofilia tissular caracterizada por eosinófilos demonstrados na biópsia pulmonar ou no lavado broncoalveolar. Embora o infiltrado inflamatório seja composto de macrófagos, linfócitos, neutrófilos e eosinófilos, a presença de eosinofilia é um marcador importante para o diagnóstico e tratamento. A apresentação clínica e radiológica pode revelar eosinofilia pulmonar simples, pneumonia eosinofílica crônica, pneumonia eosinofílica aguda, aspergilose broncopulmonar alérgica e eosinofilia pulmonar associada à doença sistêmica, como na síndrome de Churg-Strauss e na síndrome hipereosinofílica. A asma está frequentemente associada, podendo ser um pré-requisito, como na aspergilose broncopulmonar alérgica e na síndrome de Churg-Strauss. Nas doenças com acometimento sistêmico, a pele, o coração e o sistema nervoso são os órgãos mais comprometidos. A apresentação radiológica pode ser considerada como típica, ou pelo menos sugestiva, para três formas de eosinofilia pulmonar: pneumonia eosinofílica crônica, aspergilose broncopulmonar alérgica e pneumonia eosinofílica aguda. A etiologia da eosinofilia pulmonar pode ser de causa primária (idiopática) ou secundária, compreendendo causas conhecidas, como drogas, parasitas, infecções por fungos e micobactérias, irradiação e toxinas. A eosinofilia pulmonar pode também estar associada a doenças pulmonares difusas, doenças do tecido conectivo e neoplasias.

Descritores: Eosinofilia pulmonar; Síndrome hipereosinofílica; Aspergilose broncopulmonar alérgica; Sindrome de Churg-Strauss.

\footnotetext{
* Study carried out at the Júlia Kubitschek Hospital, Fundação Hospitalar do Estado de Minas Gerais - FHEMIG, Hospital Foundation of the State of Minas Gerais - Belo Horizonte, Brazil.

Correspondence to: Luiz Eduardo Mendes Campos. Rua dos Otoni, 705, sala 601, Santa Efigênia, CEP 30150-270, Belo Horizonte, MG, Brasil.
}

Tel 5531 3222-4641. Fax 5531 3226-2886. E-mail: lemendescampos@yahoo.com.br

Financial support: None.

Submitted: 16 September 2008. Accepted, after review: 6 March 2009. 


\section{General considerations}

\section{Concept}

Pulmonary eosinophilia comprises a heterogeneous group of diseases that, except for the eosinophilia aspect, have nothing in common. These diseases are defined by eosinophilia in pulmonary infiltrates (identified through bronchoalveolar lavage-BAL) or in tissue (identified through open lung or transbronchial biopsy).(1) The term "eosinophilia" is somewhat erroneous, since the infiltrate is typically composed of macrophages, lymphocytes, neutrophils and eosinophils. Lung injury typically results from all of these cells rather than from the eosinophils alone. However, eosinophilia is an important marker for diagnosis and treatment.

In the past, pulmonary eosinophilia was diagnosed on the basis of clinical findings, radiological (chest $X$-ray) findings and the presence of eosinophilia in peripheral blood. The use of BAL came to show that there are many cases in which tissue eosinophilia occurs without a concomitant increase in blood eosinophil levels, which expanded the list of diseases. ${ }^{(1)}$ In the peripheral blood, the absolute number of eosinophils is more important in characterizing eosinophilia than is the percentage. Eosinophilia is defined as peripheral when the absolute eosinophil count is greater than 500 cells $/ \mathrm{mm}^{3}$ but less than 1,000 cells $/ \mathrm{mm}^{3}$, whereas it is defined as severe when this count is greater than 1,000 cells $/ \mathrm{mm}^{3}$. In contrast, in the BAL fluid (BALF), eosinophilia is defined by the percentage of cells. In normal individuals, eosinophils account for less than 1\% of the cells in the BALF. Eosinophilia is defined as more than 5\% eosinophils, and severe eosinophilia is defined as more than $25 \%$ eosinophils.

\section{Epidemiology}

The epidemiologic factors to be considered include exposure to certain parasites (in endemic regions), toxic products (inhalation), medications and illicit drugs, as well as a history of asthma and atopy.

Various parasites can cause pulmonary eosinophilia. Tropical eosinophilia usually affects people who live in the tropics, especially in Southeast Asia, Asia and India, as well as in certain areas of China, Africa and South America. Since filarial infection is not so efficient, signifi- cant exposure typically occurs only after an individual has resided in an endemic area for months or years rather than after spending just a few days or weeks in such an area. ${ }^{(2)}$

Certain contaminations and exposures, such as those occurring after the ingestion of undercooked crustaceans (paragonimiasis) or raw meat (echinococcosis), are significant, as are those resulting from contact with contaminated water (schistosomiasis) or domestic animals, such as dogs and cats (toxocariasis). ${ }^{(3,4)}$

A history of smoking, as well as inhalation of toxic products, is significant. Acute eosinophilic pneumonia (AEP) might be related to inhalation of some new factor, such as that occurring at smoking onset, to the cleaning of gas tanks or chimneys or to significant exposure to dust or smoke, as was the case during the attacks on the World Trade Center. Recently, 18 cases of AEP were described among American soldiers deployed in lraq, all of whom were smokers-14 were recent-onset smokers, and 17 had been exposed to desert sandstorms. ${ }^{(5)}$

Drug exposure is currently a major cause of pulmonary eosinophilia. ${ }^{(6-8)} A$ long list of drugs that cause pulmonary infiltrates with eosinophilia is available on "The Drug-Induced Lung Diseases" site (www.pneumotox.com). ${ }^{(9)}$ The drugs most frequently mentioned, as of August of 2008, were the following: acetylsalicylic acid; amiodarone; bleomycin; carbamazepine; captopril; phenytoin; hydrochlorothiazide; mesalamine; minocycline; nitrofurantoin; penicillamine; sulfasalazine; and sulfonamide. lodinated contrast material and blood transfusions are also major sources of exposure.

In certain eosinophilic syndromes, such as allergic bronchopulmonary aspergillosis (ABPA) and Churg-Strauss syndrome (CSS), asthma is a prerequisite. In addition, asthma is found in $50-60 \%$ of patients with chronic eosinophilic pneumonia (CEP) and can occur in nematodeinfected patients with no history of asthma.

An epidemic of pulmonary eosinophilia occurred in Spain in 1981. This epidemic, which has come to be called the Spanish toxic oil syndrome, was caused by oil contaminated by compounds of aniline and affected approximately 20,000 people. ${ }^{(6)}$ The acute phase was characterized by eosinophilia, pulmonary infiltrates and myalgia. Another epidemic, involving L-tryptophan and affecting more than 1,400 individuals, was reported in the state of New Mexico (USA) in 1989..$^{(6,10)}$ 


\section{Radiological manifestations}

Pulmonary infiltrates, characterized by foci of air-space consolidation and focal ground-glass opacities, can be seen in pulmonary eosinophilia of all causes. ${ }^{(11)}$ However, there are certain presentations that are considered typical, or at least suggestive, of one of three groups: CEP; ABPA; and AEP. ${ }^{(11)}$

In eosinophilia, unlike in neutrophilic inflammation, cavitation is rare. Nevertheless, cavitation can occur in certain cases of ABPA and CSS, as well as in cases of certain parasitic infections, such as filariasis and hydatidosis.

\section{Laboratory findings}

Peripheral eosinophilia occurs in virtually all cases, either in the initial presentation or during the course of the disease. Eosinophilia is not always severe in blood samples, with eosinophil counts of 500-1,000 cells $/ \mathrm{mm}^{3}$, or it can even be absent from the initial clinical presentation, thereby making diagnosis difficult.

Increased eosinophil counts in the air spaces, common to various causes of pulmonary eosinophilia, result in severe eosinophilia in the BALF and is the principal method of confirming the diagnosis of AEP and CEP. In such cases, eosinophils account for more than $25 \%$ of the cells in the BALF.

Eosinophilic pneumonia due to parasites almost always occurs during larval migration to the lungs. ${ }^{(3,4)}$ Initially (in the pulmonary infiltrate phase) parasitological stool examination results are negative, because the worms are still in the larval phase and therefore do not produce eggs. Stool examination results remain negative for up to 8 weeks after the onset of pulmonary symptoms.

\section{Histopathological findings}

Lung biopsy (transbronchial or by thoracotomy) is not a prerequisite for the diagnosis of pulmonary eosinophilia. Biopsy is performed to rule out the hypotheses of infection and neoplasia, as well as to make the differential diagnosis with other interstitial diseases and cryptogenic organizing pneumonia, or to confirm CSS. Histopathological findings that are common to virtually all causes include intra-alveolar exudate of histiocytes and eosinophils, also present in the interstitium, as well as eosinophilic microabscesses, macrophages containing Charcot-Leyden crystals and findings of bronchiolitis obliterans or organizing pneumonia.(1) Small focal areas of interstitial

Chart 1 - Classification of pulmonary eosinophilia based on clinical-radiological presentation and etiology.

Principal forms of pulmonary eosinophilia (based on clinical-radiological presentation)
1) Simple pulmonary eosinophilia
2) Chronic eosinophilic pneumonia
3) Acute eosinophilic pneumonia
4) Allergic bronchopulmonary aspergillosis
5) Pulmonary eosinophilia associated with a systemic disease:
• Churg-Strauss syndrome
• Hypereosinophilic syndrome
Etiology of the forms of pulmonary eosinophilia
1) Primary or idiopathic
2) Secondary
a) Known cause
• Drugs
• Parasites
• Fuxic products/irradiation
b) Diseases that can lead to pulmonary eosinophilia
• Diffuse lung diseases: cryptogenic organizing pneumonia; hypersensitivity pneumonia; idiopathic
pulmonary fibrosis; Langerhans cell histiocytosis; sarcoidosis.
• Malignant diseases: leukemia; lymphoma; lung cancer; adenocarcinoma involving multiple organs;
squamous carcinoma involving multiple organs.
• Connective tissue diseases: rheumatoid arthritis; Sjögren's syndrome. 
fibrosis, as well as intra-alveolar necrosis and even a certain degree of vasculitis, can occur, although without granulomas. Granulomas, as well as being present in ABPA, are indicative of parasitic infections and CSS.

\section{Classification of pulmonary eosinophilia}

Chart 1 classifies pulmonary eosinophilia in terms of presentation (clinical or radiological) and etiology. ${ }^{(1,12-14)}$ The main clinical and radiological presentations are the following: simple pulmonary eosinophilia; CEP; AEP; ABPA; and pulmonary eosinophilia associated with a systemic disease, such as CSS and hypereosinophilic syndrome (HES). The etiology of pulmonary eosinophilia can be either primary (idiopathic) or secondary, due to known causes, such as drugs, parasites, fungal infection, mycobacterial infection, ${ }^{(15)}$ irradiation and toxic products. Pulmonary eosinophilia can also be associated with diffuse lung diseases, connective tissue diseases and neoplasia.

\section{Forms of pulmonary eosinophilia}

\section{Simple pulmonary eosinophilia}

In 1932, Löffler described migratory pulmonary infiltrates in patients with eosinophilia and few or no pulmonary symptoms.(1) Pulmonary infiltrates are peripheral, with a pleural base. Drugs and ascariasis are the most common causes of this syndrome. In one third of cases, simple pulmonary eosinophilia is idiopathic. The prognosis is excellent. The use of corticosteroids is rarely necessary, and spontaneous resolution occurs within 30 days. Parasitic infections and the use of drugs should be investigated even if there is spontaneous resolution. Transient pulmonary infiltrate, however, can occur in other forms of pulmonary eosinophilia, including severe diseases such as ABPA, CSS and HES.

\section{Chronic eosinophilic pneumonia}

Although CEP is a severe disease of insidious onset, with nonspecific respiratory and systemic symptoms, the radiological profile is highly suggestive of peripheral consolidation that responds promptly to corticosteroids, although it has a high recurrence rate. ${ }^{(1,16-19)}$ it can be secondary to known causes, such as drugs, parasites and irradiation for breast cancer, ${ }^{(20)}$ or be associated with rheumatoid arthritis, as well as having been described after several types of aggression, such as childbirth ${ }^{(21)}$ and desensitization using immunotherapy (allergy shots). ${ }^{(22)}$ Typically, CEP is idiopathic, and this is the most extensively studied form.

The incidence of CEP peaks in middle age. There is a predominance of females, at a ratio of $2: 1$, but this difference decreases after the age of 60 years. In one study, 82\% of the patients were over 30 years of age. ${ }^{(19)}$ In childhood, CEP is a very rare disease. Approximately $90 \%$ of all CEP patients are nonsmokers. The onset is insidious, the symptoms persisting for 2 to 4 weeks. In a retrospective study conducted in France and involving 62 cases, the most common symptoms were the following: dry cough (in 93.4\%); dyspnea (in 91.9\%); and systemic manifestations, such as fever (in 77.4\%), asthenia (in 88.3\%) and weight loss (in 75\%). ${ }^{(22)}$ Unlike what is typically seen in CSS and HES, extrapulmonary manifestations, characterized by arthralgia, pericarditis, purpura and an increase in hepatic enzyme levels, were rare in that study (affecting
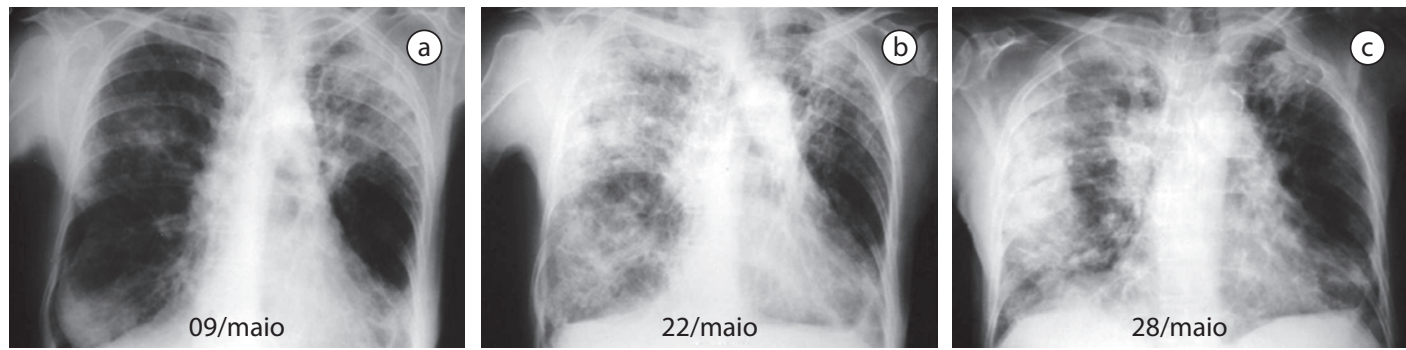

Figure 1 - Chronic eosinophilic pneumonia (idiopathic). A 71-year-old female patient with asthma and signs of systemic involvement. Blood eosinophils: 29\% (4,234 cells $\left./ \mathrm{mm}^{3}\right)$. Chest X-rays (a-c) revealing migratory pulmonary infiltrate, characterized by airspace consolidation distributed peripherally throughout the pleura. 
only 6 patients, in whom liver biopsy revealed eosinophilia).

Asthma and allergic rhinitis are present in $50-60 \%$ of cases and can precede CEP by several years. However, severe upper airway impairment is much less common in CEP than in CSS and Wegener's granulomatosis. Rare symptoms include hemoptysis, chest pain, sputum production and myalgia. There have been reports of cases in which the patients developed acute respiratory failure.

Pulmonary function test results are nonspecific, indicating normal function, mild restrictive defect or obstructive defect. In the retrospective study conducted in France, half of the patients, some of whom did not have asthma, presented or developed obstructive lung disease during the course of the disease or during the follow-up treatment. ${ }^{(22)}$ Hypoxemia or an increased alveolar-arterial oxygen gradient occurs in virtually all patients.

In 63\% of cases, the radiological profile is highly suggestive of the diagnosis and reveals peripheral pulmonary infiltrate, primarily in the pleural space. The typical profile of diffuse bilateral peripheral infiltration is found in $25 \%$ of cases (Figure 1). The main differential diagnosis should be cryptogenic organizing pneumonia or drug-induced pneumonia. ${ }^{(23)}$ Sarcoidosis can also lead to a similar radiological profile. Nonperipheral distribution of consolidations is seen in one third of cases. Rarely does CEP lead to cavitation, atelectasis, pleural effusion ${ }^{(24)}$ or nodular infiltrate. In virtually all cases, CT scans reveal bilateral peripheral foci of airspace consolidation and ground-glass opacities, even in areas considered normal on routine chest $X$-rays (Figure 2). Fibrotic opacities were seen in only 1 of the 62 patients included in the study conducted in France. ${ }^{(22)}$ Typically, interstitial fibrosis is minimal. However, there have been reports of cases in which patients developed significant fibrosis, with honeycombing and digital clubbing. ${ }^{(25)}$

The diagnosis is made based on clinical criteria, a suggestive radiological profile and the presence of peripheral eosinophilia or eosinophilia in the BALF. A rapid response to corticosteroids facilitates confirmation of the diagnosis.

Of the 62 patients included in the study conducted in France, 59 (95.2\%) were found to present severe eosinophilia (eosinophil count greater than 1,000 cells $/ \mathrm{mm}^{3}$ ), and the mean percentage of eosinophils was $30 \% .^{(22)}$ In all of the (few) cases in which eosinophilia was not identified in blood samples, the BAL findings revealed eosinophilia (greater than 25\% eosinophils in all cases and greater than $40 \%$ eosinophils in $80 \%$ of the cases). One important BAL finding in cases of CEP is that the number of eosinophils is always greater than the number of lymphocytes, in contrast to what occurs in cryptogenic organizing pneumonia, which is the principal differential diagnosis. ${ }^{(22)}$ Another important finding was that mastocytes accounted for than $0.5 \%$ of the cells in the BALF in 8 patients $(22 \%)$, only 3 of whom had asthma.

The use of corticosteroids usually leads to a dramatic improvement in symptoms in 24-48 $\mathrm{h}$,
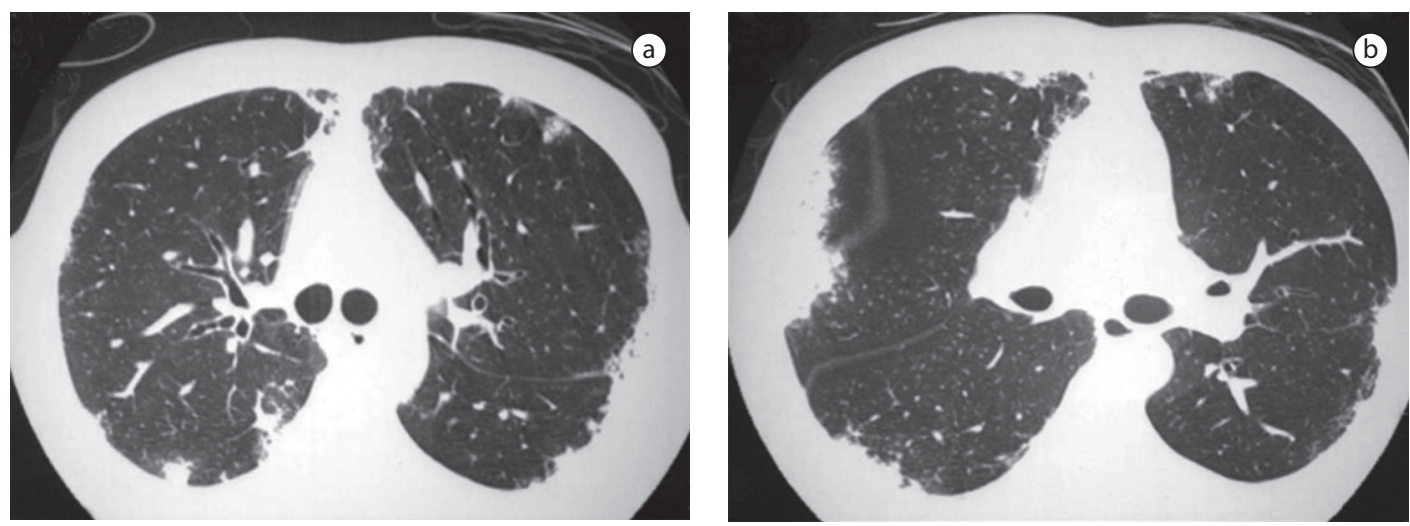

Figure 2 - Drug-induced chronic eosinophilic pneumonia. Patient diagnosed with leprosy 4 months prior and under treatment with dapsone. Blood eosinophils: 8\% (992 cells $/ \mathrm{mm}^{3}$ ). Transbronchial biopsy revealed inflammatory infiltrate consisting of lymphocytes, neutrophils and eosinophils. CT scans revealing bilateral peripheral foci of airspace consolidation. 
with a sensation of well-being and return of appetite, as well as a decrease in dyspnea, wheezing and cough. Radiological improvement typically occurs within 10 days. A report of 19 cases and a review of the literature involving 100 additional cases revealed that, in less than 2 weeks, 85\% of the patients achieved a complete response. ${ }^{(19)}$ Although the improvement was slower in the remaining patients, it occurred, in nearly all of them, within up to 30 days. Spontaneous resolution occurred in only 3 of those 19 cases. In general, spontaneous resolution is rare (occurring in only $10 \%$ of cases). Treatment with prednisone $(0.5 \mathrm{mg} / \mathrm{kg} /$ day or $30-40 \mathrm{mg} /$ day $)$ is recommended. Due to the high recurrence rate after discontinuation (58\%) or dose reduction $(21 \%)$, there is no consensus regarding treatment duration. In the study conducted in France, there was recurrence in all but 1 of the patients who used corticosteroids for less than 6 months. ${ }^{(22)}$ This suggests that 6 months is the minimum treatment duration. However, this does not mean that extending treatment beyond 6 months will prevent recurrence. Therefore, there is no reason for systematically extending treatment beyond 6 months. All episodes of recurrence respond well to corticosteroids, as in the initial occurrence. ${ }^{(16-19,22,26)}$ It has been recommended that prednisone $(0.5 \mathrm{mg} / \mathrm{kg} /$ day $)$ be used for only 6-8 weeks due to the fact that one third of patients are cured without recurrence, regardless of treatment duration, and there is a favorable response to retreatment, this favorable response persisting in the post-recurrence episodes. ${ }^{(17)}$ Inhaled corticosteroids can accelerate cure and can be used in CEP accompanied by asthma. ${ }^{(17)}$ In cases of patients without asthma, the role of inhaled corticosteroids remains undefined. Patients with concomitant asthma more often need long-term treatment due to asthma severity or recurrence.

During a follow-up period of 7 to 156 months (mean, 49 months), 10-20\% of the patients developed asthma and 7 died, although only 1 case was related to CEP. ${ }^{(19)}$ Some authors argue that there is continuity between CEP and other forms of pulmonary eosinophilia, such as CSS. ${ }^{(22)}$ Less than $10 \%$ of patients develop extrapulmonary manifestations, such as mononeuritis, pericarditis, electrocardiographic ST-segment changes, ulcerative colitis, diarrhea, arthralgia, hepatitis, purpura and urticaria.

\section{Acute eosinophilic pneumonia}

The characteristics of AEP include acute respiratory failure, fever, diffuse pulmonary infiltrate and severe eosinophilia in the BALF or in lung tissue. ${ }^{(27,28)}$ Histological examination reveals eosinophil infiltration and edema in the alveolar spaces and interstitium, including the interlobular septa. In the lung tissues, there is a release of eosinophil chemotactic cytokines, granulocyte-macrophage colony-stimulating factor (GM-CSF), $1 \mathrm{~L}-3,1 \mathrm{~L}-5$ and $\mathrm{lL}-1 \mathrm{~B}$, all of which accumulate and are seen in the BALF, without an increase in the blood. This explains tissue eosinophilia without peripheral eosinophilia. Pulmonary eosinophilia presents the greatest number of eosinophils in lung tissue, which is why, through the granules containing toxic proteins, the tissue injury is so severe. Since the proteolytic potential of eosinophils is lower than is that of neutrophils, the acute lung injury is reversible and there are no sequelae. ${ }^{(29,30)}$ Although AEP can be idiopathic, causes include drugs, parasites, fungi and inhalation of toxic products (Figure 3).
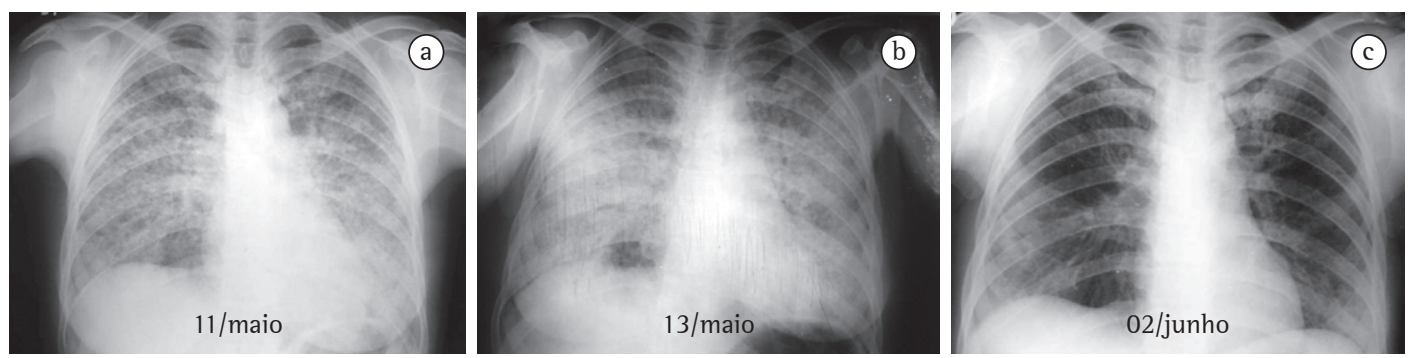

Figure 3 - Acute eosinophilic pneumonia due to a parasitic infection. Female patient admitted to the intensive care unit with fever $\left(39^{\circ} \mathrm{C}\right)$, severe dyspnea and cyanosis. Total leukocyte count: 18,100 cells $/ \mathrm{mm}^{3}$; eosinophils: $9 \%\left(1,629\right.$ cells $\left./ \mathrm{mm}^{3}\right)$. Two sputum tests using larvae of Necator sp. Chest X-rays revealing bilateral diffuse airspace consolidation (a and b) and radiological improvement, with subsequent discharge, after 2 weeks (c). 
It is of note that the onset of severe pneumonia is abrupt, occurring in less than 7 days, and, as a diagnostic criterion, never taking more than 4 weeks to develop. In a retrospective analysis of 22 cases, no differences were found between the patients with a clinical history shorter than 7 days $(n=15)$ and those in whom the duration of symptoms was 7-30 days $(n=7) .{ }^{(28)}$ This is a febrile disease, with acute respiratory failure, in which the initial diagnosis is severe community-acquired pneumonia. There are significant clinical differences between AEP and CEP. Individuals of all ages can be affected by AEP, with no female predominance. In addition, AEP is not associated with asthma. In the retrospective analysis mentioned above, there were 13 males and 9 females. Smoking is strongly correlated with AEP, especially in individuals who have recently started smoking. ${ }^{(5,31)}$ Massive inhalation of moldy hay (i.e., Aspergillus spp. mold) is another risk factor. Known causes of AEP include drugs such as sertraline, BCG, minocycline, injectable progesterone and inhaled cocaine, as well as the passage of parasites through the lung. ${ }^{(27)}$

The pulmonary infiltrate is diffuse and is not distributed peripherally. On CT scans, bilateral airspace infiltrate is seen in 93\% of the cases, and pleural effusion, usually bilateral, is seen in $71 \%$. In a case series of 12 patients, none had peripherally distributed airspace consolidation. (32) These data are in contrast to those regarding AEP, in which pleural effusion is rare. Interstitial edema can be recognized by the presence of interlobular septal thickening on CT scans.

Diagnosis is based on analysis of the BALF. Unlike in CEP (in which lymphocyte and neutrophil counts are normal), the severe eosinophilia seen in AEP (percentage of eosinophils greater than
$25 \%$ ) is accompanied by high proportions of lymphocytes $(\approx 20 \%)$ and neutrophils $(\approx 15 \%)$. The BALF analysis performed in all 22 patients revealed eosinophilia $(54.4 \pm 19.2 \%)$, and none of those patients underwent lung biopsy. ${ }^{(28)}$ In AEP, BALF analysis reveals severe eosinophilia, whereas, in acute respiratory distress syndrome (ARDS), there is a predominance of neutrophils.

Lung biopsy is performed to rule out the hypothesis of infection, especially by fungi such as Aspergillus spp. Peripheral eosinophilia (eosinophil count greater than 500 cells $/ \mathrm{mm}^{3}$ ) was detected during the course of the disease in 15 $(68 \%)$ of the 22 cases, although, typically, it is not found in the initial presentation and is not indicative of the diagnosis. Pleural effusion is eosinophilic and can facilitate the diagnosis.

Patients with AEP can be treated with methylprednisolone (60-125 mg) every $6 \mathrm{~h}$. Improvement occurs rapidly (1-3 days). In the case series of 12 patients, the airspace opacities decreased within 3 days in all patients. ${ }^{(32)}$ The dose can be reduced to $40-60 \mathrm{mg} /$ day and tapered over the subsequent 2-4 weeks.

Among the 22 patients included in the study conducted in France ${ }^{(28)}$ and in the case series of 12 patients, ${ }^{(32)} 14$ and 7 patients, respectively, needed mechanical ventilation. All patients in the two studies recovered, and 6 of the 22 did not use corticosteroids. There were no recurrences. In contrast to ARDS, AEP is not accompanied by multiple organ failure and therefore has a better prognosis.

\section{Allergic bronchopulmonary aspergillosis}

Aspergillus sp. is a type of fungus that lives in the soil and whose spores $(2-3 \mu \mathrm{m})$, when inhaled, are transformed, in the airway mucus,
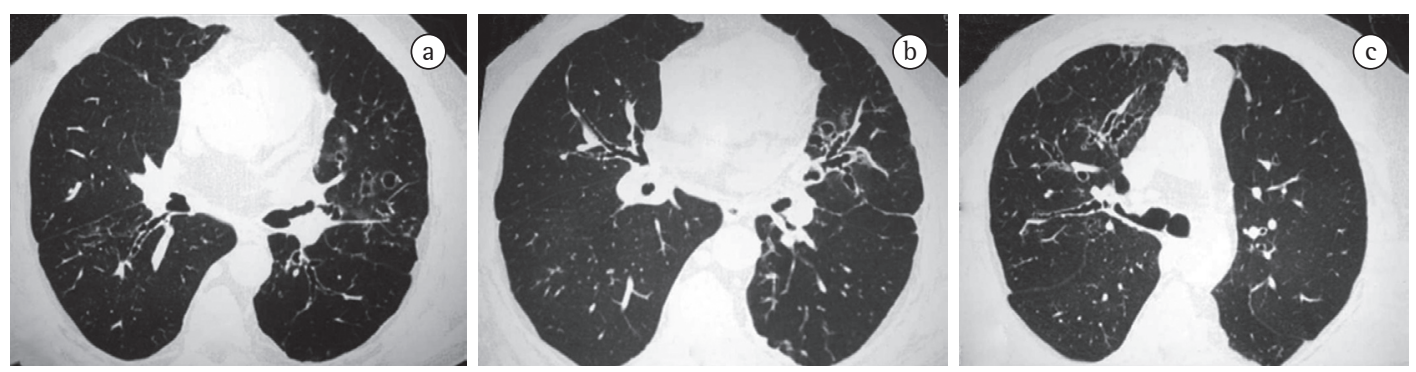

Figure 4 - Allergic bronchopulmonary aspergillosis. A 37-year-old male patient with severe, corticosteroiddependent asthma. Blood eosinophils: 12\% (1,438 cells $\left./ \mathrm{mm}^{3}\right)$; lgE level: 1,038 $\mathrm{Ul} / \mathrm{mL}$. Chest CT scans (in different planes) revealing central bronchiectasis-cylindrical, varicose and cystic (a-c). The bronchial diameter becomes normal in the periphery. 
into septate hyphae (7-10 $\mu \mathrm{m})$ with $45^{\circ}$ ramifications. Approximately $25 \%$ of asthma patients have positive immediate skin test reactivity to Aspergillus sp., which does not indicate ABPA but does indicate sensitization. Among individuals who have positive skin reactivity, only $5 \%$ meet the criteria for ABPA, that is, less than $2 \%$ of the total number of asthma patients. ${ }^{(33-39)}$

Many of the allergens that compose the hyphae are proteins with enzymatic activity that are able to damage the epithelium and allow contact between hyphae and lymphoid follicles, favoring the stimulation of Th2 cells, which results in higher $\lg \mathrm{E}$ and $\lg \mathrm{G}$ concentrations, as well as promoting eosinophil maturation and activation. The epithelial damage caused by proteases will stimulate innate immunity, with production of 1L-8, 1L-6and metalloproteinase-9, as well as neutrophil recruitment. Tissue reactions are many and varied, can be seen in combination and include bronchiectasis, eosinophilic pneumonia, bronchiolitis obliterans, bronchocentric granulomatosis, vasculitis and eosinophilic microabscesses. $^{(36)}$ Since approximately $25 \%$ of asthma patients have been previously sensitized by Aspergillus sp., the predisposition to develop ABPA seems to be related to genetic factors, such as certain mutations in HLA-DR2 antigens, that make individuals more susceptible. ${ }^{(39)}$

There is clinical suspicion of ABPA when asthma is accompanied by eosinophilia and suggestive radiological alterations, such as central bronchiectasis or pulmonary infiltrates. The incidence of ABPA peaks at the age of 30 years, and the disease typically affects individuals who have had asthma for at least 10 years. A history of expectoration of brownish sputum plugs, in the form of bronchial casts, is suggestive of a diagnosis of ABPA.

Central bronchiectasis is almost pathognomonic of ABPA, assuming that cystic fibrosis and alpha- 1 antitrypsin deficiency have been ruled out. In a study evaluating the CT scans of 17 patients with ABPA and 11 asthma patients with positive skin test reactivity to Aspergillus sp., but with no evidence of ABPA, bronchiectasis was found in 14 of the 17 patients and in only 2 of the 11 patients, respectively. ${ }^{(40)}$ In most cases, the bronchiectasis found in the patients with ABPA was centrally distributed. That study confirms that central bronchiectasis is an important diagnostic criterion, since it is not a common finding in asthma patients without ABPA. Asthma patients, when properly investigated, can present some degree of localized, focal cylindrical bronchiectasis, restricted to one or two lobes. ${ }^{(36)}$ In another study, which included 126 patients with ABPA, 73\% of the patients were found to have central bronchiectasis, and the remaining $27 \%$ were classified as having seropositive ABPA, which is defined as asthma with positive skin test reactivity to Aspergillus sp. and positive Aspergillus sp. serology, but without central bronchiectasis. ${ }^{(41)}$ Bronchiectasis is defined as central when it is found in the medial two thirds and the bronchial diameter normalizes in the periphery. ${ }^{(36)}$ It can be cylindrical, varicose or cystic (Figure 4). Expansion to the periphery in some areas or segments can occur in up to 30\% of patients. In asthma patients, V- or Y-shaped opacities can indicate mucoid impaction and are suggestive of ABPA. ${ }^{(42,43)}$ Mucoid impaction is defined as highly attenuated when the mucus density is higher than the skeletal muscle density. ${ }^{(41,44)}$ High-attenuation mucoid impaction is also pathognomonic of ABPA and was
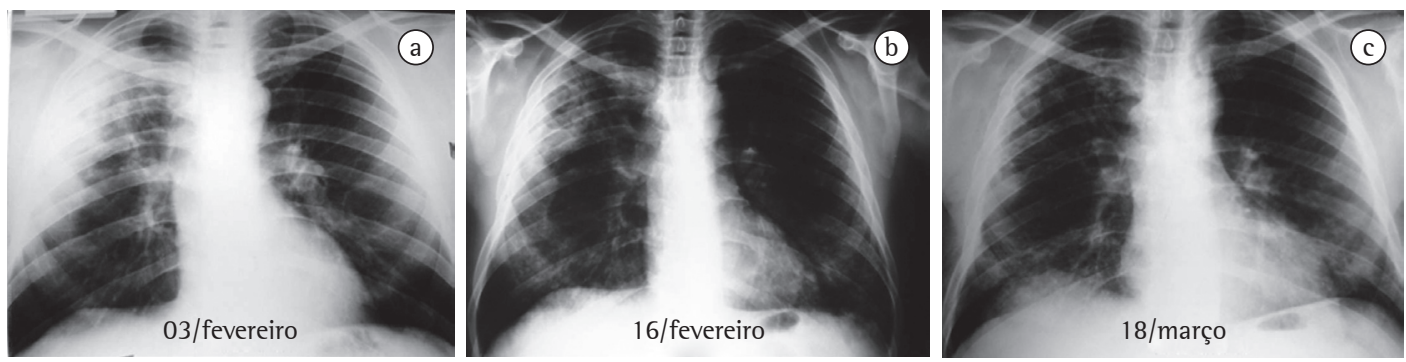

Figure 5 - Churg-Strauss syndrome. Thirty-eight-year-old male asthmatic admitted with a history of dyspnea, hemoptysis, fever, weight loss ( $10 \mathrm{~kg}$ ), paresthesia and loss of left foot strength. The patient also had pansinusitis, developed proteinuria and had a creatinine level of $1.5 \mathrm{mg} / \mathrm{dL}$. Blood eosinophils: 46\% (6,394 cells/mm $\left./ \mathrm{mm}^{3}\right)$. Initial chest X-ray revealing airspace consolidation in the right upper lobe (a). Chest X-rays revealing a subsequent area of cavitation (b) and radiological improvement after the use of prednisone (c). 
seen in $29(18.7 \%)$ of the 155 patients evaluated in another study. ${ }^{(44)}$ Such impaction is attributed to the presence of calcium salts, metals (iron and magnesium) or products of hemorrhage in the impacted mucus. It is the same base as that of the finding of fungal sinusitis. In asthma patients, pulmonary infiltrates with foci of consolidation raise the possibility of ABPA.

The following criteria are considered essential for a diagnosis of ABPA: asthma with central bronchiectasis or pulmonary infiltrates; positive skin test reactivity to Aspergillus sp.; total $\lg \mathrm{E}$ levels greater than $1,000 \mathrm{U} / \mathrm{L}$; and $\lg \mathrm{E}$ or $\lg \mathrm{G}$ against Aspergillus sp. in the blood. Criteria that are not essential but confirm the diagnosis include eosinophilia and serum precipitins to (antibodies against) Aspergillus sp. The finding of Aspergillus sp. in sputum is of value only when accompanying the essential criteria. The fungus, which is extremely common, can be inhaled and eliminated in the sputum without causing disease. Certain tests are used as a means of screening for ABPA. Positive results on these tests do not confirm the disease, although negative results rule it out. The skin test is the most important of such tests, followed by determination of total $\lg$ E levels. Negative skin test results or low lgE levels in symptomatic patients excludes the diagnosis. ${ }^{(1)}$ Asthma with central bronchiectasis and skin test reactivity to Aspergillus sp. are accepted as the minimum criteria. ${ }^{(42)}$

Based on disease activity, ABPA can be classified as having four distinct stages. The disease can be in remission, which is characterized by controlled asthma, absence of new infiltrates and normal or slightly increased lgE levels in patients who have not used oral corticosteroids for at least 6 months. Exacerbation is defined as an increase in total $\lg \mathrm{E}$ to a level double that observed at baseline, even if there is no clinical or radiological worsening. The corticosteroiddependent phase is characterized by infiltrates and increases in $\lg$ E levels due to recurring exacerbations or asthma that is controlled only with oral corticosteroids. The fibrotic phase is irreversible, with persistent dyspnea, extensive bronchiectasis with fibrosis, and chronic airflow obstruction, predominantly fixed. In this phase, there is a poor response to oral corticosteroids.

The treatment of ABPA is guided and monitored through clinical diagnosis of asthma, radiological infiltrates, pulmonary function and $\lg$ E levels. The levels of $\lg E$ should be determined every 6-8 weeks, which is the amount of time necessary for the previous levels to decrease. Exacerbations are treated with oral corticosteroids, although a favorable response to the use of inhaled corticosteroids has been reported in an isolated case. ${ }^{(45)}$

A study of 126 patients with ABPA conducted in India used a treatment regimen of prednisone at a daily dose of $0.75 \mathrm{mg} / \mathrm{kg}$, the dose being tapered at 6-week intervals. ${ }^{(41)}$ The overall treatment duration was 6-12 months. All patients presented remission after 6 weeks and were monitored for an average of 13 months (range, 9-38 months). Of the 126 patients evaluated, 25 experienced recurrence and 109 presented complete remission.

A systematic review of the literature regarding the use of antifungal agents in ABPA identified

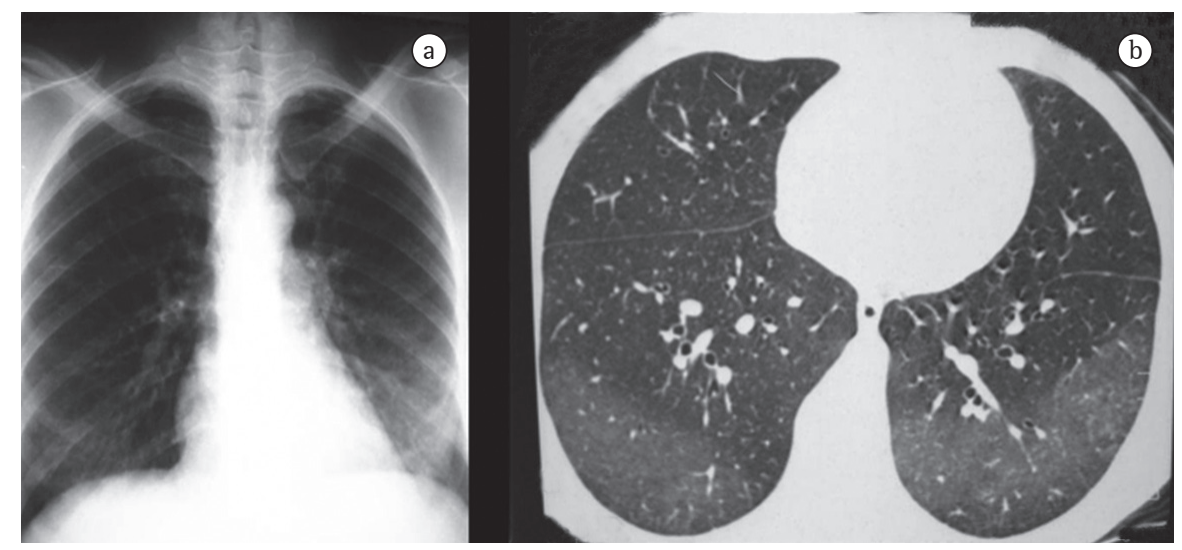

Figure 6 - Hypereosinophilic syndrome. A 39-year-old female patient with persistent eosinophilia (33-61\% eosinophils; 15,000-64,400 cells/ $\mathrm{mm}^{3}$ ) who developed leukemia during the follow-up period. Chest X-ray (a) and CT scan (b) revealing diffuse ground-glass opacity, predominantly in the lower lobes. 
only two randomized studies in which itraconazole was used. ${ }^{(46)}$ The two studies combined revealed a decrease of at least 25\% in $\lg \mathrm{E}$ levels, clinical improvement and a reduction in exacerbations, but with no effect on pulmonary function. ${ }^{(47,48)}$ One of the risks of the use of itraconazole is that it affects the metabolism of corticosteroids, potentiating their systemic effects on the adrenal gland. ${ }^{(49)} 1 \mathrm{t}$ remains debatable which group of patients with ABPA would benefit from the use of itraconazole, as well as which is the dose to be used and for how long.

\section{Churg-Strauss syndrome}

The initial description of CSS, in 1951, outlined three anatomopathological criteria: necrotizing vasculitis; tissue infiltration by eosinophils; and extravascular granulomas. ${ }^{(50,51)}$ The problem with these criteria is that they do not always coexist in time and space and are found simultaneously in a minority of cases. (52) In addition, they are not exclusive. Later, it was discovered that, in various cases, there were no biopsy findings of granulomas. The anatomopathological criteria contributed to making the disease even rarer, and very few cases were described until the criteria had been reviewed. The disease pattern has such a distinct profile that it sometimes allows the diagnosis to be made only clinically. ${ }^{(53)}$ This syndrome is characterized by three phases:

1) Allergic phase: presence of asthma or rhinitis

2) Eosinophilic phase: presence of severe persistent peripheral eosinophilia (eosinophil count greater than 1,500 cells $/ \mathrm{mm}^{3}$ ) for more than 6 months

3) Vasculitic phase: presence of systemic manifestations and small vessel vasculitis, represented by the involvement of two or more extrapulmonary organs.

However, it is important to remember that the three phases can be dissociated. Asthma is present in 100\% of cases.

Males and females are similarly affected by CSS. The prodromal phase, which can persist for several years (8-10 years), consists of lateonset asthma, which is almost always severe, preceded by allergic rhinitis. Although sinusitis can be allergic and can be accompanied by polyposis, it is rarely granulomatous and it is not as severe as it is in Wegener's granulomatosis. (54) Subsequently, there is the onset of persistent severe eosinophilia (eosinophil count greater than 1,500 cells $/ \mathrm{mm}^{3}$ ), which persists for more than 6 months. The eosinophilic phase is characterized by pulmonary infiltrates, which can be transient, typical of simple pulmonary eosinophilia or CEP. Eosinophilic gastroenteritis is more common in this phase and can lead to abdominal pain, diarrhea and bleeding. Vasculitis occurs months or years after the onset of asthma or rhinitis. The mean age at the onset of vasculitis is 38 years, and, when it occurs, asthma tends to decrease. Systemic vasculitis can be suspected based on clinical manifestations in the peripheral nervous system, the cardiovascular system and the skin. This diagnostic suspicion is strong when there is peripheral mononeuritis clinically characterized by painful paresthesia. The skin is frequently affected by palpable purpura, nodules and urticaria. Most patients have systemic manifestations, such as fever, weight loss, myalgia and arthralgia. In the heart, eosinophilic myocarditis is more common. As in HES, endomyocardial fibrosis and thrombi formation in the cardiac chambers can occur. There can also be destruction of the intracardiac valves, as well as pericarditis or difficult-to-control arterial hypertension. Cardiac manifestations signify severe impairment and contribute to half of deaths. Although renal impairment due to glomerulonephritis and characterized by hematuria and proteinuria is common, renal failure is rare. Ocular involvement, such as proptosis, is also rare, as is capillaritis with pulmonary hemorrhage. These data are in contrast to those regarding Wegener's granulomatosis, in which renal failure and ocular involvement are quite common. ${ }^{(54)}$

In certain patients with CSS and asthma, the systemic corticosteroids used in the treatment of the asthma can mask the CSS-related vasculitis, which only appears when the corticosteroids are discontinued or reduced in dosage. These are known as the formes frustes (limited forms) of CSS. ${ }^{(55)}$ Cases in which antileukotrienes were used in the treatment of asthma have been described, as have cases in which other drugs, such as fluticasone, salmeterol, macrolide antibiotics, estrogens, cocaine, paroxetine and carbamazepine, were used. It is important to emphasize that these drugs do not have a common chemical structure.

In 1990, the American College of Rheumatology established the following criteria for the diagnosis of CSS, confirmation of at 
least four being necessary: asthma; eosinophilia (eosinophil count greater than 1,500 cells $/ \mathrm{mm}^{3}$ ); paranasal sinus involvement; transient pulmonary infiltrates; mononeuropathy or polyneuropathy; and biopsy findings of vasculitis.

Therefore, the histopathological criterion of small vessel biopsy findings of extravascular eosinophils can be dispensed with if the other clinical criteria are present (Figure 5).

With these new criteria, a diagnosis of CSS has come to be more common. Skin, muscle and sural nerve biopsy can reveal perivascular eosinophilic inflammation and confirm the diagnosis. lung biopsy is considered the gold standard, although transbronchial biopsy is typically insufficient, and renal biopsy is nonspecific. Chief among biopsy findings is small vessel vasculitis associated with positivity for antineutrophil cytoplasmic antibody (ANCA), perinuclear ANCA test results being positive in $50-70 \%$ of cases. ${ }^{(56)}$ The combination of CSS and positive ANCA test results represents a more significant form of vasculitis and has therapeutic implications. ${ }^{(56)}$ A study evaluating the radiological test results of 9 patients revealed bilateral foci of nonsegmental consolidation in most of the cases. ${ }^{(57)}$

Currently, the mean survival among CSS patients is 9 years. Doses of prednisone (40-60 mg/day) for several weeks are usually necessary in order to control vasculitis and should be followed by a maintenance regimen for 1 year. If there are no clinical or laboratory manifestations of activity, the corticosteroid can be discontinued after 1 year, since recurrence is uncommon after this period. In patients who do not respond to prednisone, pulse therapy with methylprednisolone, azathioprine or cyclophosphamide is indicated.

\section{Hypereosinophilic syndrome}

A rare syndrome that typically results in death, HES presents persistent eosinophilia (eosinophil count greater than 1,500 cells $/ \mathrm{mm}^{3}$; $30-70 \%$ of total leukocyte count) for more than 6 months. It is a cause of exclusion, that is, it is necessary to exclude secondary causes such as drugs, parasites, connective tissue diseases, neoplasia and other forms of pulmonary eosinophilia (CSS and CEP). Organ involvement mainly includes the skin, the heart, the nervous system and the hematological system. The cytotoxicity of the major basic protein and eosinophil cationic protein content of eosinophils explains various instances of organ involvement in HES. The cationic protein content promotes a state of hypercoagulability, with formation of intramural thrombi in the heart, and microthrombotic events due to the endothelial lesion. In the heart, the endocardial involvement is more severe at onset.

In a retrospective study involving 50 patients, ${ }^{(58)} 32(64 \%)$ had central and peripheral nervous system involvement, including ataxia, cognitive and behavioral alterations, spasticity, peripheral polyneuropathy and cerebral infarction due to thromboembolic events. In 28 (56\%), the skin was affected, some patients presenting dermatographism, angioedema or rash. More than half of the patients had skin, heart or nervous system involvement. In 20 (40\%), the lungs were affected. Pulmonary infiltrates can be of the simple pulmonary eosinophilia, CEP or AEP type (Figure 6). There can be severe eosinophilia in the BALF.

The diagnosis is based on three criteria established by Chusid et al. ${ }^{(60)}$ : persistent eosinophilia (eosinophil count greater than 1,500 cells $/ \mathrm{mm}^{3}$ ) for at least 6 months or death within 6 months due to the signs and symptoms related to eosinophilia; eosinophilia-related involvement of at least one organ; and absence of a known cause of eosinophilia, such as drugs, parasites, malignancy, vasculitis, CEP and CSS.

There are two variants of HES. ${ }^{(59)}$ The myeloproliferative variant is a hematological disorder that belongs to the leukemia group and is accompanied by dysplasia (as revealed through myelography), hepatosplenomegaly and increased vitamin B12 levels. Such patients usually present endomyocardial fibrosis as a complication. Mastocytes seem to be involved, especially in these fibrotic reactions, and are revealed through myelography. Increased tryptase levels accompany the cardiac complications and are prognostic factors.

The lymphocytic variant results from a proliferation of Th2 cells with overexpression of the cytokines IL-3, GM-CSF and, especially, IL-5. In the lymphocytic variant, as in allergic disorders, the three organs most commonly involved are precisely the organs to which eosinophils are typically directed: the mucosal surface of the respiratory tract; the mucosal surface of the gastrointestinal tract; and the skin. In this variant, $\lg$ E levels are usually increased. Although cardiac noninvolvement improves the short-term prognosis, in the long term, there can be malig- 
nant transformation into lymphoma. Treatment includes corticosteroids, and other agents, such as anti-lL-5, have been considered.

\section{Final considerations}

A heterogenous group of diseases can lead to eosinophilia in pulmonary infiltrates or in lung tissue. In the absence of peripheral eosinophilia, the main method of investigation is BALF analysis, and the rapid response to corticosteroids helps to confirm the diagnosis. Secondary causes, such as drugs, irradiation, exposure to toxic products, parasitic infection and fungal infections, should always be investigated. However, pulmonary eosinophilia is often primary (idiopathic). Eosinophilia in lung tissue can also be associated with diffuse lung diseases, connective tissue diseases and neoplasia.

The clinical and radiological profile allows pulmonary eosinophilia to be classified as one of six distinct diseases: simple pulmonary eosinophilia; CEP; AEP; ABPA; CSS; and HES.

\section{References}

1. Allen JN, Davis WB. Eosinophilic lung diseases. Am J Respir Crit Care Med. 1994;150(5 Pt 1):1423-38.

2. Ong RK, Doyle RL. Tropical pulmonary eosinophilia. Chest. 1998;113(6):1673-9.

3. Chitkara RK, Krishna G. Parasitic pulmonary eosinophilia. Semin Respir Crit Care Med. 2006;27(2):171-84.

4. Kuzucu A. Parasitic diseases of the respiratory tract. Curr Opin Pulm Med. 2006;12(3):212-21.

5. Shorr AF, Scoville SL, Cersovsky SB, Shanks GD, Ockenhouse CF, Smoak BL, et al. Acute eosinophilic pneumonia among US Military personnel deployed in or near Iraq. JAMA. 2004;292(24):2997-3005.

6. Solomon J, Schwarz M. Drug-, toxin-, and radiation therapy-induced eosinophilic pneumonia. Semin Respir Crit Care Med. 2006;27(2):192-7.

7. Franco J, Artés MJ. Pulmonary eosinophilia associated with montelukast. Thorax. 1999;54(6):558-60.

8. Oh Pl, Balter MS. Cocaine induced eosinophilic lung disease. Thorax. 1992;47(6):478-9.

9. Pneumotox On Line [homepage on the Internet]. Dijon: Pneumotox On line. [updated 2008 April 1; cited 2008 April 19]. Available from: http://www.pneumotox.com

10. Grangeia TA, Schweller M, Paschoal IA, Zambon L, Pereira MC. Acute respiratory failure as a manifestation of eosinophilia-myalgia syndrome associated with L-tryptophan intake. J Bras Pneumol. 2007;33(6):747-51.

11. Johkoh T, Müller NL, Akira M, Ichikado K, Suga M, Ando M, et al. Eosinophilic lung diseases: diagnostic accuracy of thin-section CT in 111 patients. Radiology. 2000;216(3):773-80.

12. Durieux P, Solal-Celigny P. Pulmonary eosinophilia: current concepts, diagnostic and therapeutic advances [Article in French]. Rev Fr Mal Respir. 1981;9(1):5-26.
13. Martinet Y, Lamy P. The eosinophilic pneumonias [Article in French]. Presse Med. 1984;30(13):1833-7.

14. Wechsler ME. Pulmonary eosinophilic syndromes. Immunol Allergy Clin North Am. 2007;27(3):477-92.

15. Vijayan VK, Reetha AM, Jawahar MS, Sankaran K, Prabhakar R. Pulmonary eosinophilia in pulmonary tuberculosis. Chest. 1992;101(6):1708-9.

16. Carrington CB, Addington WW, Goff AM, Madoff IM, Marks A, Schwaber JR, et al. Chronic eosinophilic pneumonia. N Engl J Med. 1969;280(15):787-98.

17. Marchand E, Cordier JF. Idiopathic chronic eosinophilic pneumonia. Semin Respir Crit Care Med. 2006;27(2):134-41.

18. Fox B, Seed WA. Chronic eosinophilic pneumonia. Thorax. 1980;35(8):570-80.

19. Jederlinic PJ, Sicilian L, Gaensler EA. Chronic eosinophilic pneumonia. A report of 19 cases and a review of the literature. Medicine (Baltimore). 1988;67(3):154-62.

20. Cottin V, Frognier R, Monnot H, Levy A, DeVuyst P, Cordier JF, et al. Chronic eosinophilic pneumonia after radiation therapy for breast cancer. Eur Respir J. 2004;23(1):9-13.

21. Davies CW, Mackinlay $\mathrm{Cl}$, Wathen CG. Recurrent post-partum pulmonary eosinophilia. Thorax. 1997;52(12):1095-6.

22. Marchand E, Reynaud-Gaubert M, Lauque D, Durieu J, Tonnel AB, Cordier JF. Idiopathic chronic eosinophilic pneumonia. A clinical and follow-up study of 62 cases. The Groupe d'Etudes et de Recherche sur les Maladies "Orphelines" Pulmonaires (GERM"0"P). Medicine (Baltimore). 1998;77(5):299-312.

23. Zille Al, Perin C, Geyer GR, Hetzel JL, Rubin AS. Pneumonia eosinofílica crônica. J Pneumol. 2002;28(5):281-4.

24. Samman YS, Wali SO, Abdelaal MA, Gangi MT, Krayem AB. Chronic eosinophilic pneumonia presenting with recurrent massive bilateral pleural effusion: case report. Chest. 2001;119(3):968-70.

25. Yoshida K, Shijubo N, Koba H, Mori Y, Satoh M, Morikawa $\mathrm{T}$, et al. Chronic eosinophilic pneumonia progressing to lung fibrosis. Eur Respir J. 1994;7(8):1541-4.

26. Naughton M, Fahy J, FitzGerald MX. Chronic eosinophilic pneumonia. A long-term follow-up of 12 patients. Chest. 1993;103(1):162-5.

27. Allen J. Acute eosinophilic pneumonia. Semin Respir Crit Care Med. 2006;27(2):142-7.

28. Philit F, Etienne-Mastroïanni B, Parrot A, Guérin C, Robert D, Cordier JF. Idiopathic acute eosinophilic pneumonia: a study of 22 patients. Am J Respir Crit Care Med. 2002;166(9):1235-9.

29. Kariyawasam HH, Robinson DS. The eosinophil: the cell and its weapons, the cytokines, its locations. Semin Respir Crit Care Med. 2006;27(2):117-27.

30. Weller PF. The immunobiology of eosinophils. N Engl J Med. 1991;324(16):1110-8.

31. Uchiyama H, Suda T, Nakamura Y, Shirai M, Gemma $\mathrm{H}$, Shirai $\mathrm{T}$, et al. Alterations in smoking habits are associated with acute eosinophilic pneumonia. Chest. 2008;133(5):1174-80.

32. King MA, Pope-Harman AL, Allen JN, Christoforidis GA, Christoforidis AJ. Acute eosinophilic pneumonia: radiologic and clinical features. Radiology. 1997;203(3):715-9.

33. Kauffman HF, Tomee JF, van der Werf TS, de Monchy JG, Koëter GK. Review of fungus-induced 
asthmatic reactions. Am J Respir Crit Care Med. 1995;151(6):2109-15; discussion 2116.

34. Wardlaw A, Geddes DM. Allergic bronchopulmonary aspergillosis: a review. J R Soc Med. 1992;85(12):747-51.

35. Bateman ED. A new look at the natural history of Aspergillus hypersensitivity in asthmatics. Respir Med. 1994;88(5):325-7.

36. Greenberger PA. Allergic bronchopulmonary aspergillosis. J Allergy Clin Immunol. 2002;110(5):685-92.

37. Tillie-Leblond 1, Tonnel AB. Allergic bronchopulmonary aspergillosis. Allergy. 2005;60(8):1004-13.

38. Gibson PG. Allergic bronchopulmonary aspergillosis. Semin Respir Crit Care Med. 2006;27(2):185-91.

39. Slavin RG, Hutcheson PS, Chauhan B, Bellone CJ. An overview of allergic bronchopulmonary aspergillosis with some new insights. Allergy Asthma Proc. 2004;25(6):395-9.

40. Angus RM, Davies ML, Cowan MD, McSharry C, Thomson NC. Computed tomographic scanning of the lung in patients with allergic bronchopulmonary aspergillosis and in asthmatic patients with a positive skin test to Aspergillus fumigatus. Thorax. 1994;49(6):586-9.

41. Agarwal R, Gupta D, Aggarwal AN, Behera D, Jindal SK. Allergic bronchopulmonary aspergillosis: lessons from 126 patients attending a chest clinic in north India. Chest. 2006;130(2):442-8.

42. Eaton T, Garrett J, Milne D, Frankel A, Wells AU. Allergic bronchopulmonary aspergillosis in the asthma clinic. A prospective evaluation of CT in the diagnostic algorithm. Chest. 2000;118(1):66-72.

43. Shah A. Allergic bronchopulmonary aspergillosis: an Indian perspective. Curr Opin Pulm Med. 2007;13(1):72-80.

44. Agarwal R, Gupta D, Aggarwal AN, Saxena AK, Chakrabarti A, Jindal SK. Clinical significance of hyperattenuating mucoid impaction in allergic bronchopulmonary aspergillosis: an analysis of 155 patients. Chest. 2007;132(4):1183-90.

45. Balter MS, Rebuck AS. Treatment of allergic bronchopulmonary aspergillosis with inhaled corticosteroids. Respir Med. 1992;86(5):441-2.

46. Wark P. Pathogenesis of allergic bronchopulmonary aspergillosis and an evidence-based review of azoles in treatment. Respir Med. 2004;98(10):915-23.

47. Wark PA, Hensley MJ, Saltos N, Boyle MJ, Toneguzzi RC, Epid GD, et al. Anti-inflammatory effect of itraconazole in stable allergic bronchopulmonary aspergillosis: a randomized controlled trial. J Allergy Clin Immunol. 2003;111(5):952-7.

48. Stevens DA, Schwartz HJ, Lee JY, Moskovitz BL, Jerome DC, Catanzaro A, et al. A randomized trial of itraconazole in allergic bronchopulmonary aspergillosis. N Engl J Med. 2000;342(11):756-62.

49. Skov M, Main KM, Sillesen IB, Müller J, Koch C, Lanng S. latrogenic adrenal insufficiency as a side-effect of combined treatment of itraconazole and budesonide. Eur Respir J. 2002;20(1):127-33.

50. Barros JM, Antunes T, Barbas CS. Churg-Strauss syndrome. J Bras Pneumol. 2005;31(Suppl 1):S27-S31.

51. Keogh KA, Specks U. Churg-Strauss syndrome. Semin Respir Crit Care Med. 2006;27(2):148-57.

52. Capelozzi VL, Parras ER, Ab'Saber AM. Pathological manifestations of pulmonary vasculitis. J Bras Pneumol. 2005;31(Suppl 1):S9-S15.

53. Lanham JG, Elkon KB, Pusey CD, Hughes GR. Systemic vasculitis with asthma and eosinophilia: a clinical approach to the Churg-Strauss syndrome. Medicine (Baltimore). 1984;63(2):65-81.

54. Antunes T, Barbas CS. Wegener's granulomatosis. J Bras Pneumol. 2005;31(Suppl 1):S21-S6.

55. Churg A, Brallas M, Cronin SR, Churg J. Formes frustes of Churg-Strauss syndrome. Chest. 1995;108(2):320-3.

56. Radu AS, Levi M. Antineutrophil cytoplasmic antibodies. J Bras Pneumol. 2005;31(Suppl 1):S16-S20.

57. Choi YH, Im JG, Han BK, Kim JH, Lee KY, Myoung $\mathrm{NH}$. Thoracic manifestation of Churg-Strauss syndrome: radiologic and clinical findings. Chest. 2000;117(1):117-24.

58. Fauci AS, Harley JB, Roberts WC, Ferrans VJ, Gralnick $\mathrm{HR}$, Bjornson BH. NIH conference. The idiopathic hypereosinophilic syndrome. Clinical, pathophysiologic, and therapeutic considerations. Ann Intern Med. 1982;97(1):78-92.

59. Roufosse F, Goldman M, Cogan E. Hypereosinophilic syndrome: lymphoproliferative and myeloproliferative variants. Semin Respir Crit Care Med. 2006;27(2):158-70.

60. Chusid MJ, Dale DC, West BC, Wolff SM. The hypereosinophilic syndrome: analysis of fourteen cases with review of the literature. Medicine (Baltimore). 1975;54(1):1-27.

\section{About the authors}

\section{Luiz Eduardo Mendes Campos}

Coordinator of the Residency Program in Pulmonology and Respiratory Outpatient Clinic. Júlia Kubitschek Hospital, Fundação Hospitalar do Estado de Minas Gerais - FHEMIG, Hospital Foundation of the State of Minas Gerais - Belo Horizonte, Brazil.

\section{Luiz Fernando Ferreira Pereira}

Coordinator of the Asthma and Smoking Outpatient Clinic of the Residency Program in Pulmonology. Federal University of Minas Gerais Hospital das Clínicas, Belo Horizonte, Brazil. 